\title{
Measuring walkability and its effect on light rail usage: a comparative study of the USA and Japan
}

\author{
J. Nawrocki, D. Nakagawa, R. Matsunaka \& T. Oba \\ Department of Urban Management, Kyoto University, Japan
}

\begin{abstract}
With rising awareness of global warming and its consequences, greater efforts are being made to make our cities more sustainable. Among many factors that can lead to more a sustainable future, policies encouraging walking and the use of public transportation can be considered as major priorities in planning. There is a significant body of research concerning the process of rating urban structure according to its ease of access for pedestrians and concerning the relationships between walking and public transportation. However, there are few studies focused on the direct relationship between walking and Light Rail Transit (LRT). This study sought to understand the effect of the so-called walkability of urban areas on LRT usage in the USA and Japan. To achieve this goal, an objective, an internationally applicable method for quantifying walkability, was devised using urban structure and street network data in the USA and Japan. Walkability indices derived using this method was used to measure the effect of walkability in station areas on LRT ridership in both countries. Results show that the urban structure around stations in Japanese cities can generally be considered more walkable than cities in the USA. Moreover, station area walkability has a measurable effect on LRT usage, but only in the USA.

Keywords: walkability, walking, pedestrian access, LRT, transportation, urban structure, street connectivity.
\end{abstract}

\section{Introduction}

As scientific consensus continues to grow regarding the negative effects of climate change resulting from greenhouse gas emissions, cities across the globe are coming to terms with the need to reduce their environmental impact. Increasing public transportation usage and thus reducing automobile dependence, 
among others, is a necessary step in realizing a more sustainable urban future. The recent international resurgence in popularity of the urban streetcar in the form of Light Rail Transit (LRT) has made it an important part of the public transportation mix. LRT tends to be cheap compared to heavy rail and is thus politically popular [1] and as such has great potential to transform currently auto-dependent cities. Furthermore, encouraging walking as a mode of personal transportation is another way to reduce automobile use. LRT and walking are considered highly compatible transportation modes in the urban landscape due to ease of pedestrian access [2,3], but thus far there is little research that has focused solely on the direct relationship between the two.

The factors that make up the so-called walkability of a city are many, but generally fall into two broad categories of micro characteristics, often measured via subjective site audits at the local scale, and macro characteristics measured at a larger scale such as census blocks [4]. Factors such as area perceptions, aesthetics, and safety/crime can be considered part of the former group [4], while road network design characteristics such as intersection density and block length, as well as land-use diversity and population density, fall into the latter. These factors were originally coined the "three Ds," later to be expanded to include destination accessibility and distance to transit [5].

Many studies focusing on the motivators of walkability lie in the field of public health. Owen et al. [6] tested a combination of urban area characteristics and network characteristics against walking behavior, concluding that better street connectivity and proximity to destinations tended to cause higher rates of walking. Saelens et al. [7] examined the literature in the transportation and planning fields, finding that higher population density, street connectivity, and land-use mix result in more walking as transportation. Similarly, Frank et al. [8] and Leslie et al. [9] showed that walking is positively correlated with higher street network connectivity and residential density, as well as higher land-use mix. Lin and Vernez Moudon [10] tested subjective environmental measures such as perception of safety, convenience, and aesthetics, as well as objective measures such as street connectivity and density, against walking rates. Their results indicated that the objective measures tested were more likely than subjective measures to affect walking.

In the transportation and planning fields, Foltête and Piombini [11] showed that certain aesthetic measures of urban environment such as squares, commercial buildings, and trees acted positively on pedestrian frequency. In a detailed meta-analysis of literature on built environment and travel, Ewing and Cervero [5] found that land-use mix, intersection density, and proximity to destinations had the strongest relation to walking. Matsunaka et al. [12] investigated the structural differences between Japanese, French, and German regional cities in the context of rail service levels, finding that rail stations with higher service levels showed greater population density and incidence of pedestrian zones, though German cities exhibited this trend most clearly. Hass-Klau and Crampton [13] researched the success and weaknesses of LRT systems in North America, Europe, and Australia, showing that travel card use, population size in LRT line area, average LRT speed, and pedestrian street 
length per population, all had a positive effect on LRT success. Currie et al. [14] tested 57 light rail systems in North America, Australia, and Europe to determine the influences on ridership, concluding that service level, a so-called "European Factor," speed, integrated ticketing, and employment density affected ridership. This European Factor could be considered a proxy for walkability due to the high rate of pedestrianization in European cities, but was not further investigated in the study. Finally, Werner etal. [4] used micro-level and macro-level environmental measures of walkability for neighborhoods surrounding LRT stations in Salt Lake City to test against LRT usage. Micro-level characteristics such as traffic/crime safety, pedestrian amenities, aesthetics, and others were measured using the Irvine-Minnesota Inventory environmental audit. Macrolevel measures included density, land-use mix, and street network connectivity. Their findings showed that LRT usage is positively affected by walkability at both micro- and macro-level scales, but focuses only on a single city in a single country. It is clear that while urban walkability and its influence on transportation has been well documented, there is little research specific to walking and LRT, especially in the context of international comparison or Japan.

The goals of this study were twofold. First, it aimed to establish a simple and objective quantitative method for measuring walkability for the areas surrounding LRT stations in the USA and Japan. Second, it aimed to utilize the resulting walkability index in analysis to better understand the relationship between walkability and LRT usage in the USA and Japan.

\section{Analyzing the effect of walkability on LRT usage}

This study made use of objective macro-level measures of the built environment as potential factors in urban walkability. Though many walkability indices both in research and on the internet make use of more detailed (micro-level) field audits and crowd sourcing, one of the aims of this study was to avoid using such subjective data. Research by Parks and Schofer [15], Lin and Vernez Moudon [10] and Özbil and Peponis [16] has shown that objective measures of urban environment can be used in lieu of subjective measures for analysis, and in fact show strong association with walking activity. Data sets for this study were chosen with the primary concern of maintaining compatibility between American and Japanese data, and as such, data that could not be transformed to be equivalent between the two countries was left out from the study.

Selected potential walkability factors were analyzed using Principal Components Analysis (PCA) for grouping and walkability scoring. Finally, the resulting walkability index, in combination with other factors considered likely to affect LRT ridership, was tested against LRT ridership by way of linear and multiple regression analysis.

Target cities were those with LRT systems as defined in LRT: Next-generation Streetcars and Urban Development and Tramways of Japan [18]. Target LRT systems in the USA numbered 24 with a total of 1293 stations, and target systems in Japan numbered 21, with a total of 616 stations. The LRT systems are listed in Table 1 and Table 2. 
Table 1: Target Cities (USA).

\begin{tabular}{|l|l|}
\hline City & System \\
\hline Baltimore & MTA \\
\hline Boston & MBTA Green Line \\
\hline Buffalo & NFTA \\
\hline Charlotte & LYNX \\
\hline Cleveland & RTA \\
\hline Dallas & DART \\
\hline Denver & RTD \\
\hline Houston & MetroRail \\
\hline Los Angeles & Metro \\
\hline Minneapolis & MetroTransit \\
\hline New Orleans & NORTA \\
\hline Oceanside & NCTD \\
\hline Philadelphia & SEPTA \\
\hline Phoenix & Valley Metro \\
\hline Pittsburgh & Port Authority \\
\hline Portland & MAX \\
\hline Sacramento & Sacrt \\
\hline Salt Lake City & UTA \\
\hline San Diego & SDMTS \\
\hline San Francisco & Muni \\
\hline San Jose & VTA \\
\hline Seattle & Central Link \\
\hline Seattle & Seattle Streetcar \\
\hline Tacoma & Tacoma Link \\
\hline
\end{tabular}

Table 2: Target Cities (Japan).

\begin{tabular}{|l|l|}
\hline City & System \\
\hline $\begin{array}{l}\text { Arakawa } \\
\text { (Tokyo) }\end{array}$ & Arakawa Line \\
\hline Fukui & Fukubu Line \\
\hline Hakodate & Hakodate City Tram Department \\
\hline Hiroshima & Hiroshima Electric Railway \\
\hline Kagoshima & $\begin{array}{l}\text { Kagoshima City Transport } \\
\text { Bureau }\end{array}$ \\
\hline Kamakura & Enoshima Electric Railway \\
\hline Kitakyushu & Chikoho Electric Railroad \\
\hline Kochi & Tosa Electric Railway \\
\hline Kumamoto & $\begin{array}{l}\text { Kumamoto City Transportation } \\
\text { Bureau }\end{array}$ \\
\hline Kyoto & Keifuku Electric Railroad \\
\hline Matsuyama & Iyo Railway \\
\hline Nagasaki & Nagasaki Electric Tramway \\
\hline Okayama & Okayama Electric Tramway \\
\hline Osaka & Hankai Electric Tramway \\
\hline Otsu & Keihan Electric Railway \\
\hline Sapporo & $\begin{array}{l}\text { Sapporo City Transportation } \\
\text { Bureau }\end{array}$ \\
\hline $\begin{array}{l}\text { Setagaya } \\
\text { (Tokyo) }\end{array}$ & Setagaya Line \\
\hline Takaoka & Manyo Line \\
\hline Toyama & Toyama Railroad \\
\hline Toyama & Toyama Light Rail \\
\hline Toyohashi & Toyohashi Railroad \\
\hline
\end{tabular}

\subsection{Creating an index to measure walkability}

Principal Components Analysis was used to create a quantitative index of walkability. PCA is most often used for grouping correlated data into a set of aggregated synthetic variables known as components. Component scores, a by-product of the analytic process, may also be used to form data indices [19]. This study made use of these traits of PCA to group urban characteristic data and assign walkability scores to every LRT station area in the study.

Data chosen for the walkability index largely consisted of street network connectivity indicators, with additional measures that were considered possible factors in walkability. All data for the walkability index was gathered for $1 \mathrm{~km}$ radius circular buffers around every LRT station in the study (herein referred to as station zones). Other studies tend to use smaller areas for capturing walkability effects, but evidence suggests that people are willing to walk farther 
in more walkable areas [20-22]. As such, the larger $1 \mathrm{~km}$ area was chosen to avoid missing any effects of walkability that might occur further out.

The following variables were selected as possible measures of walkability:

a. Walkable street length - The total length of all streets in the station zone where pedestrian access is allowed (excludes expressways, on-ramps, and other pedestrian-prohibited roadways).

b. Intersections - The total number of intersections within the station zone. Does not include dead ends.

c. Block length - The average length of walkable streets between intersections. Calculated by dividing total walkable street length by intersections.

d. Urban land cover - The total area of land in the station zone with at least $50 \%$ coverage by impermeable surfaces.

e. Impeded pedestrian catchment area (IPCA) - A measure of pedestrian access introduced by Schlossberg [23, 24], making up the total continuouslywalkable area (by street network) with the station zone, after removing pedestrian-inaccessible roadways. Expressed as a ratio of total station zone area.

f. Dead ends - The total number of dead ends within the station zone. This includes dead ends created by removing pedestrian-inaccessible roadways.

g. Dead ends / intersections ratio - The ratio of dead ends (as measured above) to intersections within the station zone.

h. Intersection quality - The average number of street connections per intersection within the station zone.

i. Street hilliness - The standard deviation of elevation changes on all walkable streets in the station zone.

The above variables were run through PCA separately for the USA and Japan, initially without scoring in order to confirm data grouping. PCA was performed in SPSS using varimax rotation with the Eigenvalue 1 and scree plot criteria for component grouping. Table 3 and Table 4 show the resulting rotated PCA outputs for the USA and Japan. For clarity, coefficient values below -0.4 are not shown.

Table 3: PCA component grouping (USA).

\begin{tabular}{|l|l|l|l|}
\hline \multirow{2}{*}{ Variable } & \multicolumn{3}{l|}{ Component } \\
\cline { 2 - 4 } & 1 & 2 & 3 \\
\hline Intersections & 0.940 & & \\
\hline Walkable street length & 0.868 & & \\
\hline Block length & -0.807 & & \\
\hline Urban land cover & 0.510 & & \\
\hline IPCA ratio & 0.605 & -0.495 & \\
\hline Dead ends / intersections ratio & -0.447 & 0.797 & \\
\hline Dead ends & & 0.896 & \\
\hline Intersection quality & & -0.703 & \\
\hline Street hilliness & & & 0.961 \\
\hline
\end{tabular}


Table 4: PCA component grouping (Japan).

\begin{tabular}{|l|l|l|}
\hline \multirow{2}{*}{ Variable } & \multicolumn{2}{|l|}{ Component } \\
\cline { 2 - 3 } & 1 & 2 \\
\hline Intersections & 0.916 & \\
\hline Walkable street length & 0.915 & \\
\hline Block length & -0.866 & \\
\hline Urban land cover & 0.797 & \\
\hline IPCA ratio & 0.652 & \\
\hline Dead ends / intersections ratio & -0.546 & 0.667 \\
\hline Intersection quality & 0.406 & -0.577 \\
\hline Dead ends & & 0.922 \\
\hline Street hilliness & & 0.476 \\
\hline
\end{tabular}

While the number of components derived from the PCA differs between the USA and Japan, the variable groupings are largely the same. Intersections, walkable street length, block length, urban land cover, and IPCA ratio make up component 1 in both countries, and can be considered a clear indicator of walkability. The second component, made up of dead ends, dead end/intersection ratio, intersection quality, and in the case of Japan street hilliness, can be considered indicative of walking impedance. Though street hilliness occupies its own component in the USA and part of the impedance component in Japan, it is certainly not a variable, which makes up walkability.

With data grouping confirmed, the analysis was run again to assign a component (factor) score for each data point. This procedure assigned an individual walkability score for every station zone in the study. Stations were then ranked within each country and spot checked in ArcGIS to confirm that the scores were viable. The final outcome of this process was a set of two new quantitative variables to test against yearly LRT ridership: walkability and impedance. In the case of the USA where street hilliness occupied its own component in PCA, it was included in later analysis as its own variable with its original data (standard deviation of elevation).

\subsection{Testing the effect of walkability on LRT usage}

In order to understand the interaction between walkability and LRT usage, several common influences on transit ridership were tested with regression analysis against yearly LRT ridership.

The variables tested in regression analysis along with the walkability index score comprised characteristics of LRT systems, transportation connections, weather, and additional factors that were considered possible influences on LRT ridership. Variables were selected as follows:

a. Walkability - The mean walkability score of all station zones within an LRT 
system. Derived using scores for component 1 in PCA, detailed above.

b. Population - The total population within a $1 \mathrm{~km}$ buffer area of all lines within an LRT system.

c. LRT fare - The average fare of an LRT system. Calculated by dividing passenger revenue by total yearly passenger trips [25].

d. LRT headway - The average headway of an LRT system. Calculated by dividing directional route miles by average speed, then dividing by total weekday vehicles [25]. Since this data was not available in Japan, average headway was estimated using timetables.

e. LRT speed - The average speed of an LRT system. Calculated by dividing total yearly revenue $\mathrm{km}$ by revenue hours [25]. Revenue hour data is not reported in Japan, so speed was calculated by averaging speeds calculated for each LRT line in a system. Line speeds were derived by dividing one-way line length by typical transit time for that line.

f. LRT station spacing - The average spacing between stations in an LRT system. Calculated by dividing total one-way line length by total station number -1 .

g. Stations - The total number of stations in an LRT system.

h. System length - The total track length (both ways) in an LRT system.

i. Bus connections - The total number of bus connections within $100 \mathrm{~m}$ of each LRT station in a system.

j. Rail connections - The total number of rail connections within $100 \mathrm{~m}$ of each LRT station. This includes other LRT lines sharing the same station.

k. Degree days - A measure of non-ideal temperature conditions. Calculated by multiplying the number of days above or below $18.3^{\circ} \mathrm{C}$ by the number of degrees above or below $18.3^{\circ} \mathrm{C}[26]$.

1. Precipitation - Total annual precipitation (rain and snow/other).

m. City center distance - The average distance from city hall of all LRT stations in a system.

n. Walking Impedance - The mean impedance score of all station zones within an LRT system. Derived using scores for component 2 in PCA, detailed above.

o. Street hilliness - The standard deviation of elevations on all walkable streets in the station zone. Used in regression analysis for the USA .

As with the PCA procedure above, tests were performed separately for the USA and Japan. Multiple regression analysis was used to test the combination of the above variables against yearly LRT ridership. For this study a forced stepwise procedure was implemented, whereby walkability and population were first forced into the analysis. Walkability was the most desired test variable, and population was force inserted to serve as a control for differences in city size, therefore neither was removed during the analysis. Further variables were inserted in a stepwise fashion, retaining variables that most increased adjusted $\mathrm{R}^{2}$. Finally, wrong-signed and lowest $\mathrm{t}$ values were removed to reveal the relationship between walkability, population, other variables, and LRT ridership. Results for the USA and Japan exhibited marked differences. Table 5 and Table 6 show the summaries for each multiple regression analysis. 
Table 5: Multiple regression analysis (USA).

\begin{tabular}{|c|c|c|c|}
\hline Variable & $\begin{array}{l}\text { Standardized } \\
\text { Coefficient }(\beta)\end{array}$ & $\mathrm{t}$ & $\mathrm{p}$ \\
\hline (Constant) & & 2.287 & 0.034 \\
\hline Walkability & $0.322 *$ & 1.738 & 0.098 \\
\hline Population & $0.508^{* * *}$ & 2.879 & 0.010 \\
\hline Precipitation & -0.332 & -1.627 & 0.120 \\
\hline LRT Headway & $-0.316^{*}$ & -2.057 & 0.054 \\
\hline
\end{tabular}

Table 6: Multiple regression analysis (Japan).

\begin{tabular}{|l|l|l|l|}
\hline Variable & $\begin{array}{l}\text { Standardized } \\
\text { Coefficient }(\beta)\end{array}$ & $\mathrm{t}$ & $\mathrm{p}$ \\
\hline (Constant) & & -0.911 & 0.376 \\
\hline Walkability & 0.133 & 0.725 & 0.480 \\
\hline Population & $0.472 *$ & 2.100 & 0.053 \\
\hline System length & $0.574 * *$ & 2.855 & 0.012 \\
\hline City center distance & $-0.479 * *$ & -2.850 & 0.012 \\
\hline LRT speed & 0.166 & 1.119 & 0.281 \\
\hline
\end{tabular}

The above results show the clearest relationship between walkability, population, and the other variables tested. In the USA, precipitation and LRT headway combine with population and walkability to affect LRT ridership, whereas in Japan system length, city center distance, and LRT speed combine with walkability and population to affect LRT ridership. Both models fit moderately well, with over $60 \%$ of variability explained.

In the USA, population exhibits the largest influence on ridership with a standardized coefficient of 0.508 , demonstrating the fact that as city size increases, so too should ridership. LRT headway shows a negative relationship with ridership, corroborating previous research that shorter headway yields greater ridership [27]. Precipitation exhibits a negative effect on ridership, as perhaps riders are unwilling to wait in the rain at LRT stops. Its effect is insignificant, however, with a $\mathrm{p}$ value of 0.120 . Finally, walkability, though not significant at the 0.05 level, does have an effect on LRT ridership. As for Japan, population is not significant at the 0.05 level, but does seem to affect ridership. System length, which is significant with the largest standardized coefficient of 0.574 , has the greatest effect on ridership. City center distance also has a significant effect on LRT ridership, indicating that LRT ridership was higher in cities whose LRT system is on average closer to the city center. LRT speed also interacts with the other variables, but has no significant effect on ridership. Walkability in Japan does not appear to have an effect on ridership. 
The most important distinction to make between analyses for the USA and Japan is that though walkability in combination with other variables does have a measurable effect on LRT ridership in the USA, no viable combination of variables in Japan show walkability as having an effect on ridership. Whereas the $\mathrm{p}$ value for walkability in the USA is 0.098 , the $\mathrm{p}$ value for walkability in Japan is 0.480 . It is clear that walkability has no influence on LRT ridership in Japan, using the currently-selected variables.

\section{Discussion}

The goals of this study were to create an objective and quantitative index of macro walkability, and to use that index to understand the relationship between walkability and LRT usage in the USA and Japan. To do so, data was gathered for several measures of urban structure and street network connectivity, for $1 \mathrm{~km}$ radius circular buffers around every station in target LRT systems in the USA and Japan. Principal Components Analysis was used on these possible walkability measures, resulting in a pair of walkability indices for the USA and Japan that were strikingly similar in terms of variable grouping. Those indices were used to test walkability and other variables against LRT ridership using multiple regression analysis. Results from the analysis show that in combination with select variables, walkability does have a positive, if moderate, effect on LRT ridership in the USA. However, the same is not the case in Japan.

Why might walkability not affect LRT ridership in Japan while it does in the USA? One possibility is that Japan already has more walkable urban structure surrounding LRT stations, as well as less variability in walkability between stations and between cities. Indeed, running a new PCA without separating American and Japanese cities shows that the mean walkability score of Japanese cities is higher than American cities. An individual t-test demonstrates that the mean walkability score in Japan $(0.30 \pm 0.05)$ is higher than that of the USA $(-0.14 \pm 0.05)$, with a statistically-significant difference of 0.44 (95\% CI, 0.35 to $0.53), \mathrm{t}(1331.07)=9.641, \mathrm{p}<.0005$. Figure 1 illustrates that not only do mean walkability scores differ between the two countries, but the range of scores is much broader in the USA than in Japan. With walkable urban structure already successfully established in Japanese target cities; it is possible that walkability does not vary enough between Japanese cities to influence LRT usage as tested.

\subsection{Challenges and further study}

One of the major limitations of this study lies in the nature of available data. Since data was chosen to be consistent between both the USA and Japan, what was available presented a much smaller set of data than what would normally be desirable for testing. Crime, for example, can have a large impact on the walkability of a station zone [28], but data for crime in Japan is not available in a consistent format that could be matched with American crime data. 


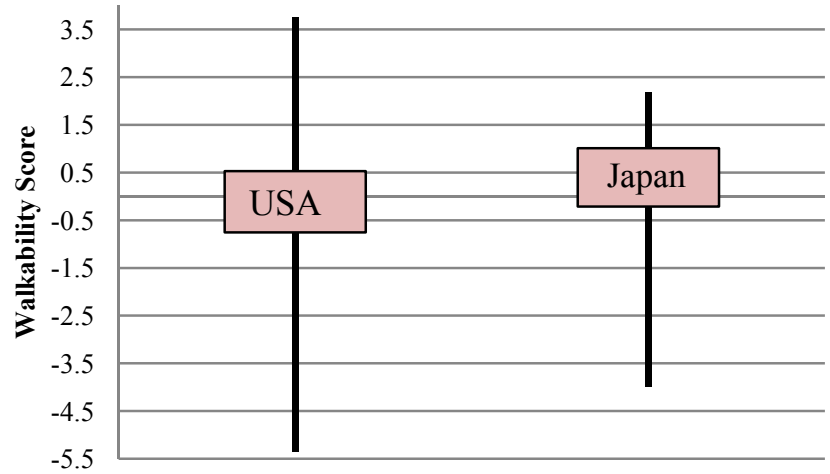

Figure 1: Walkability score range, 25th/75th percentile (USA and Japan).

Additionally, basing measures of macro walkability on street network data has its own inherent problems. The most trustworthy street data for both the USA and Japan is GIS line data available from each national government, and lacks detailed street information. Streets that were considered walkable for this study were simply those streets where pedestrians are allowed by law. There is no accounting in the data for whether or not a street is actually pedestrian friendly or hostile. This is an especially pertinent issue in comparing between the USA and Japan, as Japanese urban structure, often with narrow streets and many intersections, differs greatly from American urban structure, especially in relatively newer cities. Data for sidewalks or pedestrian paths or even road width could do much to alleviate this issue, but at the present time there is no consistent data available for both the USA and Japan.

Future study will include analysis of the relationship between walkability and LRT usage at the level of individual LRT lines. With a higher level of detail, it is possible that more subtle relationships between walkability and other variables and LRT usage can be determined, both in the USA and in Japan.

\subsection{Conclusion}

This study showed that using Principal Components Analysis for quantifying walkability yields similar and useable results in both the USA and Japan. This method has the potential to be applied to any city worldwide where the same street network data is available. Though it lacks a level of detail that could be obtained by subjective judgment and field audits, as a broad indicator of the walkability of urban structure it could be of great use to planners. Furthermore, walkability as measured by street connectivity has a limited but measurable effect on LRT ridership in the USA. Though street network-based walkability does not appear to have a measurable effect on LRT ridership in Japan, it is clear that walkability around LRT stations in Japanese cities is higher than in American cities. These conclusions alone demonstrate an interesting phenomenon deserving of a more detailed investigation. 


\section{References}

[1] Black, A., The Recent Popularity of Light Rail Transit in North America. Journal of Planning Education and Research, 12, pp. 150-159, 1993.

[2] Zacharias, J., The Amsterdam Experiment in Mixing Pedestrians, Trams and Bicycles. ITE Journal, 69(8), pp. 22-28, 1999.

[3] Topp, H.H., Innovations in tram and light rail systems. Proceedings of the Institution of Mechanical Engineers Part F, 213, pp. 133-141, 1999.

[4] Werner, C.M., Brown, B.B. \& Gallimore, J., Light rail use is more likely on "walkable" blocks: further support for using micro-level environmental audits. Journal of Environmental Psychology, 30, pp. 206-214, 2010.

[5] Ewing, R. \& Cervero, R., Travel and the Built Environment. Journal of the American Planning Association, 76(3), pp. 265-294, 2010.

[6] Owen, N., Cerin, E., Leslie, E., duToit, L. \& Coffee, N., Neighborhood Walkability and the Walking Behavior of Australian Adults. American Journal of Preventative Medicine, 33(5), pp. 387-394, 2007.

[7] Saelens, B.E., Sallis, J.F. \& Frank, L.D., Environmental Correlates of Walking and Cycling: Findings From the Transportation, Urban Design, and Planning Literatures. The Society of Behavioral Medicine, 25(2), pp. 80-91, 2003.

[8] Frank, L.D., Schmid, T.L., Sallis, J.F. \& Chapman, J., Linking Objectively Measured Physical Activity with Objectively Measured Urban Form. American Journal of Preventative Medicine, 28(2S2), pp. 117-125, 2005.

[9] Leslie, E., Saelens, B., Frank, L., Owen, N., Bauman, A., Coffee, N. \& Hugo G., Residents' perceptions of walkability attributes in objectively different neighbourhoods: a pilot study. Health \& Place, 11, pp. 227-236, 2005.

[10] Lin, L. \& Vernez Moudon, A., Objective versus subjective measures of the built environment, which are most effective in capturing associations with walking? Health \& Place, 16, pp. 339-348, 2010.

[11] Foltête, J. \& Piombini, A., Urban layout, landscape features and pedestrian usage. Landscape and Urban Planning, 81, pp. 225-234, 2007.

[12] Matsunaka, R., Oba, T., Nakagawa, D., Nagao, M. \& Nawrocki, J., International comparison of the relationship between urban structure and the service level of urban transportation - A comprehensive analysis in local cities in Japan, France and Germany. Transport Policy, 30, pp. 26-39, 2013.

[13] Hass-Klau, C. \& Crampton, G., Future of Urban Transport - Learning from Success and Weakness: Light Rail, Environmental and transport planning: Brighton, 2002.

[14] Currie, G., Ahern, A. \& Delbosc, A., Exploring the drivers of light rail ridership: an empirical route level analysis of selected Australian, North American and European systems. Transportation, 38, pp. 545-560, 2011.

[15] Parks, J. \& Schofer, J.L., Characterizing neighborhood pedestrian environments with secondary data. Transportation Research Part D, 11, pp. 250-263, 2006. 
[16] Özbil, A. \& Peponis, J., Modeling street connectivity, pedestrian movement and land-use according to standard GIS street network representations: A Comparative Study. Proceedings, 6th International Space Syntax Symposium, Istanbul, pp. 018-01-018-10, 2007.

[17] Utsunomiya, K. \& Hattori, S., LRT: Next-generation Streetcars and Urban Development, Seizando: Tokyo, pp. 23-27, 2010. (in Japanese).

[18] Japan Tramway Society, Tramways of Japan, 2011 Edition, Japan Tramway Society: Tokyo, 2011. (in Japanese).

[19] Vyas, S. \& Kumaranayake, L., Constructing socio-economic status indices: how to use principal components analysis. Health Policy and Planning, 21(6), pp. 459-468, 2006.

[20] Canepa, B., Bursting the Bubble - Determining the Transit-Oriented Development's Walkable Limits. Transportation Research Record: Journal of the Transportation Research Board, 1992, pp. 28-34, 2007.

[21] Lee, C. \& Vernez Moudon, A., The 3Ds + R: Quantifying land use and urban form correlates of walking. Transportation Research Part D, 11, pp. 204-216, 2006.

[22] Mehdi Moeini, S.M., Pedestrian Oriented City: Assessing the Impact of Environment on Pedestrian Movement in Tehran, Lambert Academic Publishing: Saarbrücken, 2011.

[23] Schlossberg, M., From TIGER to Audit Instruments - Measuring Neighborhood Walkability with Street Data Based on Geographic Information Systems. Transportation Research Record: Journal of the Transportation Research Board, 1982, pp. 48-56, 2006.

[24] Schlossberg, M. \& Brown, N., Comparing Transit-Oriented Development Sites by Walkability Indicators. Transportation Research Record: Journal of the Transportation Research Board, 1887, pp. 34-42, 2004.

[25] Integrated National Transit Database Analysis System, Florida Department of Transportation, Online. http://www.ftis.org/intdas.html

[26] Degree Days FAQ, Weather Underground, Online. http://www.wunderground.com/about/faq/degreedays.asp?MR=1

[27] Currie, G. \& Rose, J., Growing patronage - Challenges and what has been found to work. Research in Transportation Economics, 22, pp. 5-11, 2008.

[28] Kim, S., Ulfarsson, G. \& Hennessy, J.T., Analysis of light rail rider travel behavior: Impacts of individual, built environment, and crime characteristics on transit access. Transportation Research Part A, 41, pp. 511-522, 2007. 